This is a peer-reviewed, accepted author manuscript of the following paper: Navas de Maya, B., Kurt, R. E., \& Turan, O. (2019). Marine accident learning with fuzzy cognitive maps (MALFCMs): a case study on fishing vessels. Paper presented at European Safety and Reliability Conference, Hannover, Germany.

\title{
Marine Accident Learning with Fuzzy Cognitive Maps (MALFCMs): A Case Study on Fishing Vessels
}

\author{
B. Navas de Maya \\ Department of Naval Architecture, Ocean \& Marine Engineering, University of Strathclyde, UK. E-mail: \\ beatriz.navas-de-maya@strath.ac.uk \\ R. E. Kurt \\ Department of Naval Architecture, Ocean \& Marine Engineering, University of Strathclyde, UK. E-mail: \\ rafet.kurt@strath.ac.uk

\section{O. Turan} \\ Department of Naval Architecture, Ocean \& Marine Engineering, University of Strathclyde, UK. E-mail: \\ o.turan@strath.ac.uk
}

\begin{abstract}
Despite advanced safety systems installed on ships, marine accidents still occurs at a more-or-less constant rate. This situation can be attributed to the fact that accidents occurred in a complex way and the role of humans into past accidents is not properly understood in this process. Furthermore, a number of factors are combined to result in a failure/accident but interrelations of these factors are not well understood. Therefore, shipping industry can benefit from a practical method, which is capable of considering the interrelations and identifying the importance weightings for each factor involved in an accident. Thus, in this paper, a new technique for Marine Accident Learning with Fuzzy Cognitive Maps (MALFCMs) is developed and demonstrated. The method utilises Fuzzy Cognitive Maps (FCMs) to model the relationships by also integrating information from an accident database. By applying accident data instead of expert judgement, MALFCMs may overcome the main disadvantage of FCMs by controlling the subjectivity in results attributed to expert opinion. Within this study, MALFCMs is applied to fishing vessels accident data, in order to compare the results with the findings of an existing report provided by the European Maritime Safety Agency (EMSA). In order to make this comparison, Collision and Fire/explosion accidents were selected and comparatively analysed in this paper. Our study shows that MALFCM can produce results, which are in line with the findings from aforementioned EMSA report.
\end{abstract}

Keywords: Maritime Accidents, Maritime Safety, Fishing Vessels, Fuzzy Cognitive Maps (FCMs), MALFCM.

\section{Introduction}

Maritime transport has been characterized by ship accidents since its origins, incurring in significant economic consequences and social impact, as established by Eliopoulou, Papanikolaou et al. (2016). With the aim to prevent aforementioned accidents, the shipping industry has implemented numerous safety measures to improve overall maritime safety. Nevertheless, despite all the efforts accidents are still happening, remaining a major concern when considering that around 90\% of world trading is carried out by the maritime sector according to Chauvin, Lardjane et al. (2013).

When analysing statistics regarding industrial causalities, human factor are identified as the major cause in at least $66 \%$ of the accidents and more than $90 \%$ of the incidents in various industries such as aerospace or nuclear according to Azadeh and Zarrin (2016) findings. In addition, O'Hare, Wiggins et al. (1994) established than in aviation between $70 \%$ and $80 \%$ of the accidents were attributed to human errors. Furthermore, within the maritime context, an average of $80 \%$ of Proceedings of the 29th European Safety and Reliability Conference.

Edited by Michael Beer and Enrico Zio

Copyright (C2019 by ESREL2019 Organizers. Published by Research Publishing, Singapore

ISBN: 981-973-0000-00-0 :: doi: 10.3850/981-973-0000-00-0 esrel2019-paper the accidents are attributed to some sort of human error (Rothblum 2000, Graziano, Teixeira et al. 2016, Turan, Kurt et al. 2016).

As it is clear from the literature than human actions have a high impact into accident, the purpose of this paper is first to identify all human factors that contributes to the development of an accident, and second, to obtain the weighting of aforementioned human factors. Hence, this paper applies a FCM based technique, Marine Accident Learning with Fuzzy Cognitive Maps (MALFCMs), and demonstrates it through a case study on fishing vessels.

\section{Methodology}

The objectives of this paper are first, to apply MALFCM method to identify and obtain the weighting of each accident contributing factor involved in collision and fire/explosion accidents in fishing vessels; and second, to compare the results obtained by applying MALFCM with the findings of an existing report provided by EMSA. In order to complete aforementioned aims, the following steps are followed: 
First, the FCM basic theory is introduced. Second, MALFCM method is presented and explained. Third, the considerations and limitation of this study are highlighted. In addition, the accident contributing factors that are responsible for collision and fire/explosion accidents in fishing vessels are highlighted. Finally, the results and discussion section includes the final weight distribution of accident contributing factors in collision and fire/explosion categories, and the comparison with EMSA findings.

\subsection{Fuzzy cognitive maps (FCMs) basic theory}

When analysing a complex scenario (e.g. a maritime accident), the classification of the contributing factors involved appears to be one of the main issues according to Wolpert (1992). The problem associated with how to select the best classification technique has been previously addressed in the literature by Aggarwal (2014), who identified for instance Bayesian Networks (BNs), or decision trees methods. However, although these methods provide excellent performance, there is no technique that could be selected as the best method for all datasets as Fernández-Delgado, Cernadas et al. (2014) concluded.

Other alternative for classification of new data is the application of the FCM method, which has been employed in the last years in different fields. Although it is not as well-known as other methods (Papakostas, Boutalis et al. 2008, Papakostas, Koulouriotis et al. 2012), it has been proved by Vergini and Groumpos (2016) that FCM are very promising and worth of further investigation and development. In addition, several studies have applied FCMs as a classification tool in different fields, e.g. in medicine (Kannappan, Tamilarasi et al. 2011, Papageorgiou and Kannappan 2012, Papageorgiou, Oikonomou et al. 2012) or information technology (Büyüközkan and Vardaloğlu 2012).

Therefore, due to the vagueness and data unavailability regarding maritime accidents, and the fact that this study requires data collected from past experiences, a method that can deal with both requirements, as the FCMs method does, should be applied (Azadeh, Salehi et al. 2014).

There are numerous definition regarding FCM in the literature. For instance, Eden (1988) defines FCMs as extensions of cognitive maps which aim to model complex chains of casual relationships. Cognitive maps were created by Axelrod (1976) in the 1970s, aiming to represent social scientific knowledge. Then, evolving from cognitive maps, Kosko (1986) developed fuzzified cognitive maps, mainly characterised by three components: the factors characterizing the system, and signed and weighted arcs indicating the strength of each interrelation.

\subsubsection{Composition and mathematical representation of an FCM}

Each FCM can be developed through three main components. First, an interaction matrix with dimension $\mathrm{n} \times \mathrm{n}$, where $\mathrm{n}$ indicates the number of factors characterizing the system. A zero value in the matrix indicates that a relation does not exist between two particular factors, while non-zero factors show not only that there is a relation but also its strength. Second, an initial state vector, which shows the value of the factors in the scenario being modelled at any point in time $(\mathrm{t})$. Finally, a threshold function. There are numerous threshold functions available, however, the sigmoid function gives any possible value within the interval $[0,1]$ (Xiao, Chen et al. 2012, Azadeh, Salehi et al. 2014). Thus, the application of the sigmoid function provides greater benefits (Bueno and Salmeron 2009). Within a FCM, León, Rodriguez et al. (2010) establish that it is possible to identify three types of connections between each pair of factors, based on the nature of their relationship:

- A positive value between the weights of factors $\mathrm{Ci}$ and $\mathrm{Cj}$ (Wij $>0$ ), which means that an increase in the first factor will lead to an increase in the second factor. Moreover, if the first factor is decreased the second factor will be also decreased.

- A negative value between the weights of factors $\mathrm{Ci}$ and $\mathrm{Cj}(\mathrm{Wij}<0)$, which means that an increase in the first factor will lead to a decrease in the second factor. Moreover, if the first factor is decreased the second factor will be increased.

- No causality (Wij=0) which indicates that two factors are not interrelated.

Thus, a traditional formula to calculate the values of the factors in an FCM is shown in Eq. (1) (Kosko 1986):

$$
A_{i}^{(t+1)}=f\left(A_{i}^{(t)}+\sum_{j=1, j \neq 1}^{n} W_{j i} A_{j}^{(t)}\right)
$$

In which $A_{i}^{(t+1)}$ represents the value of the factor $\mathrm{C}_{\mathrm{i}}$ at the step $\mathrm{t}+1$, f symbolizes the threshold function, $W_{j i}$ denotes the weight between both concepts $\mathrm{C}_{\mathrm{i}}$ and $\mathrm{C}_{\mathrm{j}}$, and $A_{j}^{(t)}$ indicates the value of the concept $\mathrm{C}_{\mathrm{j}}$ at step $\mathrm{t}$.

In order to create a FCM, Eq. (1) is applied as an iterative process for each time step (step 1, step 2 etc.) until the process ends, which could happen 
in three different scenarios (Kosko 1994, Khan, Quaddus et al. 2001, Xiao, Chen et al. 2012):

- The FCM reaches equilibrium. After two consecutive steps repeating the process both state vectors obtained are identical. Hence, the simulation stop, and the FCM is considered steady.

- The FCM does not produce a stable result. This situation occurs when the results keep cycling between a set of values without stabilizing. This condition is known as the "limit cycle".

- The FCM does not reach identical values. The FCM produces different state vectors each step ("chaos" situation) and it can appear in complex scenarios.

The next section in this paper shares the details of the approach adopted, which utilizes a new methodology known as Marine Accident Learning with Fuzzy Cognitive Maps (MALFCMs).

\subsection{Marine accident learning with fuzzy cognitive maps (MALFCMs)}

As it was previously mentioned, FCM is a very promising method to classify new data. However, its main shortcoming is the likelihood to restrict the resulting outcome due to experts' lack of knowledge. In order to overcome this disadvantage, MALFCMs method is proposed with the aim to establish weightings for human factors involved into accidents successfully. Therefore, the results from MALFCMs method can be considered more objective, as this new approach combines historical accident data and expert opinion, overcoming the main disadvantage of traditional fuzzy cognitive maps (i.e. the subjective results and knowledge deficiencies between experts).

The construction of a MALFCM model might be achieved through the analysis of historical accident data, by reflecting expert judgement or as the combination of both. Nevertheless, it has been designed with the purpose to better capture the state of maritime safety from both past accidents and reliable experience. Then, a combination of historical occurrence data and expert judgement within MALFCM is strongly recommended. Thus, MALFCMs structure could be described in four main stages:

- $\quad$ Stage 1: Historical Data

- $\quad$ Stage 2: Expert Opinion

- $\quad$ Stage 3: FCM

- Stage 4: Consolidation of Results
First, the Historical data stage collects data for accidents with a specific profile (e.g. same navigational accident), in order to identify which human factors were involved in the accident case study. Then, each pair of factors is compared to create an interaction matrix, which establishes the relative importance of concepts and the causal effects between nodes. For example, to obtain the relation between factors $C_{i}$ and $C_{j}$, the historical accident database is filtered by the accidents caused by any of these two factors, in order to calculate how often these two factors have been recorded into past accidents. Then, the database is filtered by the accidents that register together $\mathrm{C}_{\mathrm{i}}$ and $\mathrm{C}_{\mathrm{j}}$ as a common accident cause. Following this process, the weight of $\mathrm{C}_{\mathrm{i}}$ over $\mathrm{C}_{\mathrm{j}}$ is established as the relation between the accidents with both factors in common and the accidents with $\mathrm{C}_{\mathrm{i}}$ but not $C_{j}$. Moreover, the weight of $C_{j}$ over $C_{i}$ is defined as the relation between the accidents with $\mathrm{C}_{\mathrm{i}}$ and $\mathrm{C}_{\mathrm{j}}$ and the accidents with $\mathrm{C}_{\mathrm{j}}$ but not $\mathrm{C}_{\mathrm{i}}$. This process is repeated in order to fill the interaction matrix. In addition, the state vector is defined as the statistical occurrence of each human factor. Second, in the Expert opinion stage, experts are requested to provide their knowledge by comparing each pair of factors identified from the historical accident database. Then, an interaction matrix and a state vector are created for each expert individually. Moreover, a generic interaction matrix and state vector are created by combining each individual interaction matrix and state vector. Third, in the FCM stage, the threshold function is selected, and two FCMs are created by following Eq. (1). The first FCM is created with the interaction matrix and the state vector obtained from the Historical data stage. In addition, the second FCM integrates the interaction matrix and the state vector obtained from the expert judgement. For both FCMs created, the results are analyzed, and the obtained weightings are ranked. Lastly, in the consolidation of result stage, final weightings are obtained as a combination from the historical data and expert judgement results.

It is important to mention that for this study expert judgement was not included, as it was purely based on data collection. Therefore, from MALFCMs method, only the "historical data stage" and the "FCM stage" are applied to this case study.

\subsection{Considerations and limitations of this study}

For the completion of this study, the following considerations and limitation have been taken into account:

- EMSA report was based on a European accident database. The data for this study was 
obtained from MAIB, and it comprises maritime accidents involving UK vessels worldwide and all vessels operating in UK territorial waters.

- EMSA report have a different accident outcome than MAIB database. Hence, only those categories that appears in both sources under the same name are considered within this study i.e. collision and fire/explosion.

- The report provided by EMSA analyzed fishing vessels with LOA or LBP greater than or equal to $15 \mathrm{~m}$. Therefore, the same consideration was taken for this study.

- EMSA analyzed data between June 2011 and August 2017, while this study considers accidents between June 2011 and 2016 (last information obtained).

\subsection{Accident contributor factors involved in collision and fire/explosion accidents in fishing vessels}

The factors that are considered within this study are obtained from analysing a database provided by the Marine Accident Investigation Branch (MAIB). This data was selected as it includes information regarding human factors contribution into past accidents. Thus, the data obtained for this case study registers marine accidents involving UK vessels worldwide and all vessels operating in UK territorial waters for the period 2011-2016.This period was selected for this study in order to compare the results with the report provided by EMSA. From all the ninety four accident contributor factors included in the database, only a total of fourteen were identified for collision accidents on fishing vessels, while just eleven were found responsible of fire/explosion accidents. Moreover, some of these factors, e.g. "Lack of knowledge" or "Lack of skills", were found in both accidents outcomes.

Table 3 below shows the factor numbers assigned to each accident contributor involved in collision and fire/explosion accidents on fishing vessels. In addition, Table 4 shown the weightings for each accident contributor obtained from the FCM (defined on the interval $[0,1]$ ) and the weightings normalised (as the \% contribution of each factor into accidents).

\section{Results and Discussions}

In order to create a FCM, it is required to obtain first an interaction matrix, and second a state vector by following the process explained in section 2.1.

Due to the size of the interaction matrix, Table 1 shows only a partial representation of the interaction matrix for collision accidents in fishing vessels for the period 2011-2016. Thus, for this case study, the state vector was defined as the statistical occurrence of each factor. Thus, Table 2 provides a partial representation of the initial state vector (St.0) for collision accidents in fishing vessels for the period 2011-2016. In addition, Table 2 also provides the dynamic evolution of the FCM until equilibrium is reached.

Table 1. Partial interaction matrix for collision accidents in fishing vessels until equilibrium is reached. Period 2011-2016.

\begin{tabular}{llllll}
\hline & HF1 & HF7 & $\ldots$ & HF48 & HF50 \\
\hline HF1 & X & 0.00 & $\ldots$ & 0.00 & 0.00 \\
HF7 & 0.00 & X & $\ldots$ & 1.00 & 1.00 \\
$\ldots$ & $\ldots$ & $\ldots$ & $\ldots$ & $\ldots$ & $\ldots$ \\
HF48 & 0.00 & 0.50 & $\ldots$ & X & 0.50 \\
HF50 & 0.00 & 1.00 & $\ldots$ & 1.00 & X \\
\hline
\end{tabular}

Table 2. Partial state vector and calculation of steady state for collision accidents in fishing vessels until equilibrium is reached. Period 2011-2016.

\begin{tabular}{llllll}
\hline & HF1 & HF7 & HF8 & $\ldots$ & HF50 \\
\hline St.0 & 0.33333 & 0.33333 & 0.33333 & $\ldots$ & 0.33333 \\
St.1 & 0.58257 & 0.95257 & 0.66076 & $\ldots$ & 0.95257 \\
St.2 & 0.64166 & 0.99970 & 0.75920 & $\ldots$ & 0.99970 \\
St.3 & 0.65513 & 0.99980 & 0.77888 & $\ldots$ & 0.99980 \\
St.4 & 0.65817 & 0.99980 & 0.78226 & $\ldots$ & 0.99980 \\
St.5 & 0.65885 & 0.99980 & 0.78283 & $\ldots$ & 0.99980 \\
St.6 & 0.65900 & 0.99980 & 0.78293 & $\ldots$ & 0.99980 \\
St.7 & 0.65904 & 0.99980 & 0.78295 & $\ldots$ & 0.99980 \\
\hline
\end{tabular}

Once the interaction matrix and the state vector have been defined, the FCM is created by applying Eq. (1) until equilibrium is reached.

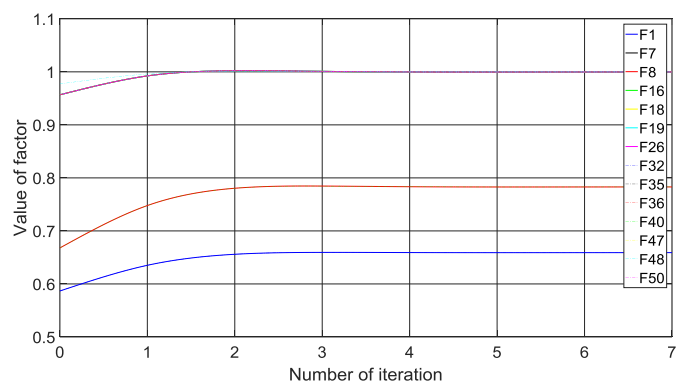

Fig. 1. Values of FCM for collision accidents in fishing vessels until equilibrium is reached. Period 2011-2016.

Figure 1 shows as an example the iteration process followed in the FCM created for collision accidents until equilibrium is reached, which 
occurs before step 5 in this case. In addition, Table 4 shows the final weightings obtained for all accident contributors, after the FCM reaches equilibrium and the simulation stops.

Table 3. Factor numbers assigned to each accident contributor involved in collision and fire/explosion accidents on fishing vessels.

\begin{tabular}{|c|c|}
\hline $\begin{array}{l}\text { Factor } \\
\text { No }\end{array}$ & Factor Name \\
\hline 1 & Anthropometric factors, dimensions \\
\hline 3 & Design error \\
\hline 6 & Emergency training program \\
\hline 7 & Expectations of supervisor is unclear \\
\hline 8 & Frequent change of watch schedule \\
\hline 11 & Improper performance of maintenance/repair \\
\hline 15 & $\begin{array}{l}\text { Inadequate procedures and check lists } \\
\text { (ship/port, maintenance, company, emergency, } \\
\text { other) }\end{array}$ \\
\hline 16 & Inadequate promotion of safety \\
\hline 18 & Inadequate training programme \\
\hline 19 & Inadequate work methods \\
\hline 26 & Lack of knowledge \\
\hline 29 & Lack of motivation/morale \\
\hline 32 & Lack of skills \\
\hline 35 & Long working periods, much overtime \\
\hline 36 & Low job satisfaction, monotony \\
\hline 40 & LTA mental and psychological state \\
\hline 42 & LTA planning \\
\hline 46 & Regulatory standards \\
\hline 47 & Resistance to change \\
\hline 48 & Safety awareness, cutting corners \\
\hline 50 & Too high work load/load work load \\
\hline 51 & Training ignored \\
\hline
\end{tabular}

Moreover, according to Table 4, it is possible to observe that there is a steady distribution regarding human-factor weightings. Thus, there is a set of human factors with a weighting of $7.76 \%$, which includes all human factors with the highest contribution into collision accidents in fishing vessels (e.g. Factor 48 - "Safety awareness, cutting corners"). Moreover, HF 1 and HF 32 have the minimum contribution into collision accidents.

Furthermore, regarding fire/explosion, Factor 51 - "Training ignored" has the maximum impact, while Factor 46- "Regulatory standards" is the factor that contribute the least into fire/explosion accidents.
Table 4. Weightings and normalised weightings for each accident contributors involved in collision and fire/explosion accidents on fishing vessels.

\begin{tabular}{|c|c|c|c|}
\hline $\begin{array}{l}\text { Factor } \\
\text { No }\end{array}$ & $\begin{array}{l}\text { Event } \\
\text { Description }\end{array}$ & $\begin{array}{l}\text { Weight } \\
\text { (FCM) }\end{array}$ & $\begin{array}{l}\text { Weight } \\
(\%)\end{array}$ \\
\hline 1 & Coll. & 0.66 & 5.12 \\
\hline 7 & Coll. & 1.00 & 7.76 \\
\hline 8 & Coll. & 0.78 & 6.08 \\
\hline 16 & Coll. & 1.00 & 7.76 \\
\hline 18 & Coll. & 1.00 & 7.76 \\
\hline 19 & Coll. & 1.00 & 7.76 \\
\hline 26 & Coll. & 1.00 & 7.76 \\
\hline 32 & Coll. & 0.66 & 5.12 \\
\hline 35 & Coll. & 1.00 & 7.76 \\
\hline 36 & Coll. & 1.00 & 7.76 \\
\hline 40 & Coll. & 0.78 & 6.08 \\
\hline 47 & Coll. & 1.00 & 7.76 \\
\hline 48 & Coll. & 1.00 & 7.76 \\
\hline 50 & Coll. & 1.00 & 7.76 \\
\hline 3 & $\mathrm{~F} / \mathrm{E}$ & 0.77 & 9.34 \\
\hline 6 & $\mathrm{~F} / \mathrm{E}$ & 0.56 & 6.86 \\
\hline 11 & $\mathrm{~F} / \mathrm{E}$ & 0.83 & 10.03 \\
\hline 15 & $\mathrm{~F} / \mathrm{E}$ & 0.77 & 9.34 \\
\hline 26 & $\mathrm{~F} / \mathrm{E}$ & 0.70 & 8.54 \\
\hline 29 & $\mathrm{~F} / \mathrm{E}$ & 0.77 & 9.34 \\
\hline 32 & $\mathrm{~F} / \mathrm{E}$ & 0.83 & 10.03 \\
\hline 42 & $\mathrm{~F} / \mathrm{E}$ & 0.83 & 10.03 \\
\hline 46 & $\mathrm{~F} / \mathrm{E}$ & 0.50 & 6.08 \\
\hline 48 & $\mathrm{~F} / \mathrm{E}$ & 0.70 & 8.54 \\
\hline 51 & $\mathrm{~F} / \mathrm{E}$ & 0.98 & 11.87 \\
\hline
\end{tabular}

\subsection{Findings from EMSA}

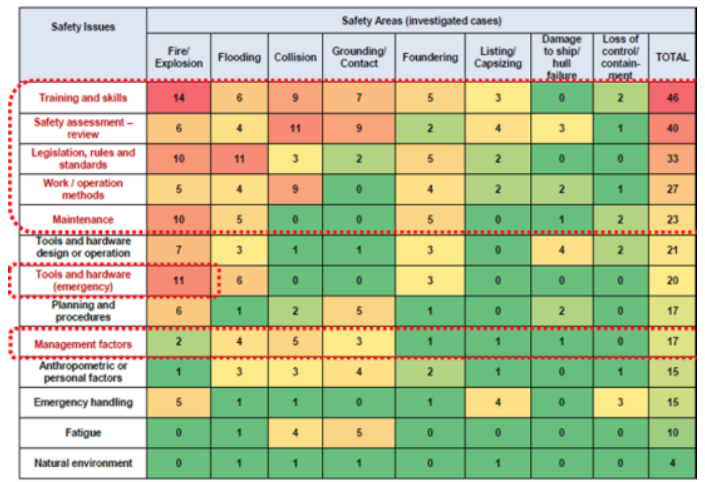

Fig. 2. Risk assessment table for casualties with ships provided by EMSA. Period 2011-2017. (EMSA 2018).

As it can be observed by comparing the findings from this study and the report provided by EMSA, 
a safety problem is identified as the major contributing factor into collision accidents. Also for collision, work methods and inadequate training are the second most contributing factor from the report, which obtained the second highest weighting from this study. For fire/explosion, for both reports the most contributing factor is training ignored.

\section{Conclusions}

In this paper, a model based on Fuzzy Cognitive Maps theory, MALFCM, was applied to a case study on fishing vessels. The final aim was to compare the results with an existing report that was released by EMSA. However, due to existing differences between both nomenclatures, just two accident categories (Collision and Fire/explosion) were compared within this paper. For collision accidents, a lack of safety was identified as the top contributing factor, while for Fire/explosion, a lack of training and skills was found the most contributing factor.

The novelty of MALFCM lays in the application of FCMs theory to model the relationships of accident contributors by utilizing information obtained from an accident database, with the ability to combine expert opinion. Hence, since the initial information is derived from historical data, the results could be considered more objective, and MALFCM may overcome the main disadvantage of FCMs by eliminating or controlling the subjectivity in results attributed to experts uncertainty.

Nevertheless, as it is possible to observe from this paper, there are some differences when comparing both studies regarding how data is collected, mainly due to taxonomy differences between MAIB and EMSA databases. Therefore, aforementioned differences make it difficult to compare both reports effectively. Moreover, the report from EMSA has identified thirteen Safety Issues (SI) based partially on professional judgement as shown in Figure 2. As EMSA criteria to define these SI was unknown, it was decided to maintain for this study each accident contributing factor as mentioned in MAIB accident database, identifying a total of fourteen accident contributing factors for collision accidents, and eleven factors for fire/explosion accidents, as shown in Table 4.

In addition, human factor contribution into past accidents is a recent issue, and therefore available data is a concern, as accident investigators have just recently started to incorporate human factors into accident reports. Hence, there is an additional risk when studying specific cases (e.g. collision accidents in fishing vessels) as the data points might not be enough to ensure reliable results. Thus, an alternative solution would be to combine the results from historical accident data with expert knowledge (i.e. to apply MALFCM method completely) in order to provide more reliable results.

Finally, as a future work recommendation, a more detailed study could include to group MAIB factors by following EMSA professional judgement, which would reduce the complexity when comparing the results obtained from both reports. Also the data analysed within this study differed from EMSA data, since EMSA has access to a European accident database, while data for this study was taken from MAIB, and limited to accidents with UK vessels or accidents within UK territorial waters. Hence, a more complex study could be perform at a European level.

\section{Acknowledgement}

The authors of this paper would like to acknowledge the assistance of the Marine Accident Investigation Branch (MAIB) for providing the required data for performing this study.

This research study was supported by EU funded H2020 SAFEMODE Project (Grant Agreement No 814961).

\section{References}

Aggarwal, C. C. (2014). Data Classification: Algorithms and Applications, CRC Press.

Axelrod, R. M. (1976). Structure of Decision: The Cognitive Maps of Political Elites, Princeton University Press.

Azadeh, A., V. Salehi, M. Arvan and M. Dolatkhah (2014). "Assessment of resilience engineering factors in high-risk environments by fuzzy cognitive maps: A petrochemical plant." Safety Science 68: 99-107.

Azadeh, A. and M. Zarrin (2016). "An intelligent framework for productivity assessment and analysis of human resource from resilience engineering, motivational factors, HSE and ergonomics perspectives." Safety Science 89: 55-71.

Bueno, S. and J. L. Salmeron (2009). "Benchmarking main activation functions in fuzzy cognitive maps." Expert Systems with Applications 36(3): 5221-5229.

Büyüközkan, G. and Z. Vardaloğlu (2012). "Analyzing of CPFR success factors using fuzzy cognitive maps in retail industry." Expert Systems with Applications 39(12): 10438-10455.

Chauvin, C., S. Lardjane, G. Morel, J.-P. Clostermann and B. Langard (2013). "Human and organisational factors in maritime accidents: Analysis of collisions at sea using 
the HFACS." Accident Analysis \& Prevention 59: 26-37.

Eden, C. (1988). "Cognitive mapping." European Journal of Operational Research 36(1): 1-13.

Eliopoulou, E., A. Papanikolaou and M. Voulgarellis (2016). "Statistical analysis of ship accidents and review of safety level." Safety Science 85: 282-292.

EMSA (2018). "Analysis on marine casualties and incidents involving fishing vessels."

Fernández-Delgado, M., E. Cernadas, S. Barro and D. Amorim (2014). "Do we need hundreds of classifiers to solve real world classification problems." J. Mach. Learn. Res 15(1): 31333181 .

Graziano, A., A. P. Teixeira and C. Guedes Soares (2016). "Classification of human errors in grounding and collision accidents using the TRACEr taxonomy." Safety Science 86: 245257.

Kannappan, A., A. Tamilarasi and E. I. Papageorgiou (2011). "Analyzing the performance of fuzzy cognitive maps with non-linear hebbian learning algorithm in predicting autistic disorder." Expert Systems with Applications 38(3): 1282-1292.

Khan, M., M. Quaddus and A. Intrapairot (2001). Application of a Fuzzy Cognitive Map for Analysing Data Warehouse Diffusion. Applied informatics-proceedings.

Kosko, B. (1986). "Fuzzy cognitive maps." International journal of man-machine studies 24(1): $65-75$.

Kosko, B. (1994). "The new science of fuzzy logic: fuzzy thinking." HarperCollins, LondonLane DC, Oliva R (1998) The greater whole: towards a synthesis of the system dynamics and soft system methodology. Eur J Oper Res 107(1998): 214235Lee.

León, M., C. Rodriguez, M. M. García, R. Bello and K. Vanhoof (2010). Fuzzy cognitive maps for modeling complex systems. Mexican International Conference on Artificial Intelligence, Springer.

O'Hare, D., M. Wiggins, R. Batt and D. Morrison (1994). "Cognitive failure analysis for aircraft accident investigation." Ergonomics 37(11): 1855-1869.

Papageorgiou, E. I. and A. Kannappan (2012). "Fuzzy cognitive map ensemble learning paradigm to solve classification problems: Application to autism identification." Applied Soft Computing 12(12): 3798-3809.

Papageorgiou, E. I., P. Oikonomou and A. Kannappan (2012). Bagged nonlinear hebbian learning algorithm for fuzzy cognitive maps working on classification tasks. Hellenic Conference on Artificial Intelligence, Springer.
Papakostas, G. A., Y. S. Boutalis, D. E. Koulouriotis and B. G. Mertzios (2008). "Fuzzy cognitive maps for pattern recognition applications." International Journal of Pattern Recognition and Artificial Intelligence 22(08): 1461-1486.

Papakostas, G. A., D. E. Koulouriotis, A. S. Polydoros and V. D. Tourassis (2012). "Towards Hebbian learning of fuzzy cognitive maps in pattern classification problems." Expert Systems with Applications 39(12): 10620-10629.

Rothblum, A. M. (2000). Human error and marine safety. National Safety Council Congress and Expo, Orlando, FL.

Turan, O., R. E. Kurt, V. Arslan, S. Silvagni, M. Ducci, P. Liston, J. M. Schraagen, I. Fang and G. Papadakis (2016). "Can We Learn from Aviation: Safety Enhancements in Transport by Achieving Human Orientated Resilient Shipping Environment." Transportation Research Procedia 14: 1669-1678.

Vergini, E. S. and P. P. Groumpos (2016). "A new conception on the Fuzzy Cognitive Maps method." IFAC-PapersOnLine 49(29): 300304.

Wolpert, D. H. (1992). "Stacked generalization." Neural networks 5(2): 241-259.

Xiao, Z., W. Chen and L. Li (2012). "An integrated FCM and fuzzy soft set for supplier selection problem based on risk evaluation." Applied Mathematical Modelling 36(4): 1444-1454. 